\title{
(6) OPEN ACCESS \\ Conflict escalation in paediatric services: findings from a qualitative study
}

\author{
Liz Forbat, ${ }^{1}$ Bea Teuten, ${ }^{2}$ Sarah Barclay ${ }^{2}$
}

${ }^{1}$ School of Health Sciences, University of Stirling, Stirling, UK

${ }^{2}$ Medical Mediation

Foundation, London, UK

Correspondence to Sarah Barclay, Director Medical Mediation Foundation

36 Westbere Road, London NW2 3SR, UK: sarah.barclay@ medicalmediation.org.uk

Received 23 October 2014 Revised 28 January 2015 Accepted 3 April 2015 Published Online First 4 May 2015

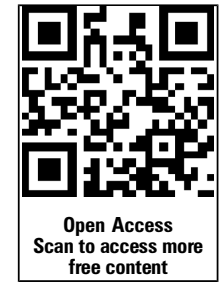

CrossMark

To cite: Forbat $\mathrm{L}$, Teuten $\mathrm{B}$, Barclay S. Arch Dis Child 2015:100:769-773.

\section{ABSTRACT \\ Objective To explore clinician and family experiences of conflict in paediatric services, in order to map the trajectory of conflict escalation.}

Design Qualitative interview study, employing extremecase sampling. Interviews were analysed using an iterative thematic approach to identify common themes regarding the experience and escalation of conflict.

Participants Thirty-eight health professionals and eight parents. All participants had direct experience of conflict, including physical assault and court proceedings, at the interface of acute and palliative care.

Setting Two teaching hospitals, one district general hospital and two paediatric hospices in England, in 2011. Results Conflicts escalate in a predictable manner. Clearly identifiable behaviours by both clinicians and parents are defined as mild, moderate and severe. Mild describes features like the insensitive use of language and a history of unresolved conflict. Moderate involves a deterioration of trust, and a breakdown of communication and relationships. Severe marks disintegration of working relationships, characterised by behavioural changes including aggression, and a shift in focus from the child's best interests to the conflict itself. Though conflicts may remain at one level, those which escalated tended to move sequentially from one level to the next.

Conclusions Understanding how conflicts escalate provides clinicians with a practical, evidence-based framework to identify the warning signs of conflict in paediatrics.

\section{INTRODUCTION}

Conflict between healthcare staff, patients and families presents a burden to individuals and to healthcare systems, including burnout, absenteeism and higher turnover. ${ }^{1}$ Conflict has been defined as a multidimensional construct, involving a process whereby two or more people perceive opposition of another, ${ }^{2}$ and a process whereby one's interests, norms and values are opposed by another. ${ }^{3}$ Such conflict may be 'vertical' between staff and patients, or 'horizontal' between clinicians. ${ }^{4}$

The incidence and prevalence of conflict has been the focus of a small number of studies. Intensive care units (ICUs) provide a ripe environment for developing conflict, with a mixture of very sick patients, high mortality, multiple specialities and a frequent need for urgent decisions on complex matters. ${ }^{5}$ The epidemiology of conflict in observational studies of adult ICUs has been reported as ranging from 32\% (for nurse-doctor conflict $)^{6}$ up to $78 \%$ among relatives of patients in ICUs where there is doubt about use of continued life-supporting treatment. ${ }^{7}$ A study of conflict in

\section{What is already known on this topic?}

- Conflict between healthcare staff and patients/ families present a burden to individuals and healthcare systems.

- Treatment advances in paediatric care, with attendant shifts in survival and morbidity outcomes, create a ripe environment for conflicts to develop.

\section{What this study adds?}

- A trajectory of conflict escalation is described which indicates that conflicts move through mild, moderate and severe phases.

- As conflicts worsen trust deteriorates, with the evolution of separate camps and micromanagement of care, before behavioural changes and a disintegration of working relationships.

- The profound nature of severe conflict suggests that urgent interventions are warranted.

one paediatric intensive care unit (PICU) identified that nearly half of the sample of 110 families reported conflict. ${ }^{8}$ Communication is often identified as a significant contributor to conflict. ${ }^{9-11}$ Conflicts in adult and paediatric ICUs have considerable similarities, despite their very different contexts. ${ }^{8}$

Various aspects of paediatric services mirror the ICU stressors. The multipartner nature of medical encounters (such as the triad dynamic in paediatrics of clinicians, patient and parents) increases the complexity of cases and thereby augments the potential for disagreement and conflict. ${ }^{12}$ Advances in life-sustaining interventions mean that more babies and children live longer, ${ }^{13}$ but with the potential for greater morbidity. ${ }^{14}{ }^{15}$

Clinical implications arising from treatment advances and lengthened life expectancy include an increase in decisions regarding the burdens and benefits of treatment and increasingly complex decisions regarding the merit of intensive or invasive treatments. ${ }^{16}$ Different views regarding withholding or withdrawing life-sustaining treatments can lead to impaired communication between clinicians,${ }^{17}$ as well as between clinicians, patients and relatives. ${ }^{18}$ If not identified and resolved at an early stage, these entrenched differences in view may lead to court action, ${ }^{19}$ which is both fiscally and 
emotionally costly, ${ }^{16}$ but are often resolved without such intervention. $^{2021}$

The aim of this project was to explore health professional and family experiences of conflict in paediatric services, in order to map the trajectory of conflict escalation.

\section{METHODS}

A semi-structured qualitative interview method was adopted. Participants were initially identified through purposive sampling of health professionals working at the interface of acute and palliative services, in PICUs, neonatal intensive care units and children's hospices. Initial interviewees were asked to pass their study details to colleagues using the snowball sampling technique. $^{22}$ All participants self-defined as having personal experience of 'serious disagreement' or 'conflict' about medical care. All clinicians approached consented to participate; three parents did not respond to the invitation. The sample consisted of 46 participants, including doctors $(n=20)$, nurses $(n=10)$, parents $(n=8)$, chaplains $(n=3)$, lawyers $(n=2)$, Patient Advice and Liaison Service (PALS) managers $(n=2)$ and hospice head of care $(n=1)$, from two teaching hospitals, one district general hospital and two children's hospices, in England. The majority of health professional respondents worked in PICU, with some in general services.

Interview questions prompted discussion of conflict between health professionals and families, intrafamily conflict and intraprofessional conflict, with interviewees asked to describe such experiences focusing on the characteristics of conflict. They were also invited to describe the way in which conflicts escalated.

Interviews lasted between 30 and $90 \mathrm{~min}$. They were transcribed and anonymised, then subjected to an iterative thematic analysis. $^{23}$ Analysis proceeded through a five-stage process. Stage 1 involved familiarisation with the dataset. Stage 2 involved identifying a thematic framework. Stage 3 involved indexing the data with reference to the thematic framework. In Stage 4, responses were synthesised from across respondents into a working grid of themes. Stage 5 focused on data interpretation and finalisation of key themes arising from the data. Analysis was conducted by BT and SB, with a subsample being analysed independently by LF to verify the emergent themes. The phases of conflict escalation emerged from the data and were verified in later interviews where participants were asked to comment on the veracity and accuracy of the three phases.

National Health Service Research Ethics approval was granted by Surrey REC (11/H1109/4). All participants gave written informed consent.

\section{RESULTS}

Phases of conflict and markers of escalation

Data analysis identified key characteristics for the escalation of conflicts. Clearly identifiable events and behaviours by both clinicians and families were grouped into mild (poor management of relationships with the family), moderate (deterioration of trust) and severe (disintegration of working relationships), as illustrated in table 1. Conflicts did not always escalate; however, those which did tended to move through each phase in sequence, with two or more features of each phase being apparent in respondents' accounts.

\section{Mild: poor management of relationships with the family}

Characteristic features of the mild stage involved communication, specifically, clinicians using language insensitively and giving conflicting messages. Concerns about care management and a history of unresolved conflict were also evident.

Insensitive use of language: One respondent reported a case where a clinician described a child as 'moribund' in front of family members, and that this was enough to 'start a germ' that 'grows and festers to cause a breakdown in trust' (healthcare lawyer). The following quotation describes the way a prognosis was delivered to the parent:

14 people came into the room, led by two professors who proceeded to inform us that they had done a liver biopsy, they were looking for something that would give them confirmation that she had [name of condition], if she had [the condition] she would be dead within the next month or so, if she didn't have [the condition] they expected her to be dead by Christmas, and if she didn't die by Christmas she would be a vegetable for the rest of her life, which they anticipated to be very short. And then they turned round and left. (Parent)

Conflicting messages: Another indication for conflict escalation was where a family received mixed messages about their child's prognosis or treatment. Inconsistencies within the treating team led to a loss of trust. In a PICU, for example, a child's prognosis may change regularly and different teams, or members of a team, may provide apparently contradictory information to families:

Perhaps the advice that we've given has conflicted at the bedside, and so [the family] thought, 'well none of them are in agreement, why should I listen to them'. (Sister, PICU)

Care management concerns: Perceived or genuine errors in the treatment or management of a child, currently or in the past could also result in increased parental anxiety and distrust. An unaddressed error, or a decision which had long-lasting or profound consequences for a child, could have an impact on how a family perceived their care:

I think that goes back to the resuscitation really, right back to his birth. The people involved then clearly got it completely wrong so [the family believed] they're never going to get it right again, despite the fact that people who had made those decisions had retired by the time all this happened. (Consultant paediatrician)

History of unresolved conflict: Previous experiences of conflict over treatment decisions led to them becoming 'sensitised' to the risk of a disagreement escalating. Some healthcare

Table 1 Phases of conflict escalation

\begin{tabular}{lll}
\hline Mild: poor management of relationships with the family & Moderate: deterioration of trust & Severe: disintegration of working relationships \\
\hline Insensitive use of language & Repetitive arguments leading to entrenchment & Child is no longer the focus \\
Conflicting messages & Avoidance & Conflict takes on a life of its own \\
Care management concerns & Micromanagement & Physical and verbal threats \\
History of unresolved disagreement & Faction building & Attack \\
\hline
\end{tabular}


professionals learnt only when they were taking over the care of a child from a colleague, that the family was already engaged in taking legal action over disagreements about treatment.

One doctor who had been involved in a number of high profile cases explained:

My other warning sign actually is... about broken relationships [...] if I then get a lot of distress from other professionals around it makes me think, why is this? (Consultant in Palliative Care)

\section{Moderate: deterioration of trust}

In the moderate stage, conflicts began to change dynamically and escalate more significantly. Communication difficulties initially experienced in the mild stage become amplified and begin to impact family-clinician relationships with the deterioration of trust resulting in faction building and parents' micromanaging care.

Repetitive arguments leading to entrenchment: The data suggest that families who questioned clinicians or who did not agree with the treatment proposed were labelled as 'awkward'. With repetitive conversations, each party defended their position more forcefully. If neither party showed willingness to listen or negotiate, then communication became entrenched:

\begin{abstract}
What you see more and more are families who have very entrenched positions mirrored by staff who have very entrenched positions, and that especially if you are talking about intensive care cases or end-of-life cases, there is a certain degree of security in the staff's entrenched position; they perceive a sense of security, they know where they are if they draw firm lines and don't budge, that is a sign of weakness, perhaps in front of colleagues and in front of the family. (PALS Manager)
\end{abstract}

Avoidance: Both clinicians and families engaged in avoidance behaviours, for example, by not attending meetings or avoiding discussions of the issues underlying the conflict. As one respondent explained:

[The mum] very deliberately chose to arrive on a Thursday or Friday, knowing those to be the days when I wouldn't challenge her. (Consultant in palliative care)

Micromanagement: As trust broke down, families begin to monitor and question their child's care and treatment in detail. This meticulous scrutiny resulted in staff feeling mistrusted and conflict escalating:

[The family] were standing over the nurses watching what they were doing. Every time somebody went anywhere near the child one of the parents was there watching. The nurses then felt; 'we're not being trusted here, we're professionals, we've got to get on with our job, let us get on with our job.' (Healthcare lawyer)

Faction building: A further characteristic of this phase occurred as healthcare professionals and parents felt more alienated and misunderstood. Factions built up with both sides finding others to foster support for their position. As a result, more people were drawn into the conflict:

You are no longer dealing with the mother and father, but you are dealing with a huge band, which can include significant people like grandparents and [...] some leaders of their faith. (PALS manager).

From that time on [clinicians saying that nutrition could not be withheld] I was quite suspicious really of the medical establishment and/or the hospice in pretty much in every way [...] I was on the alert and lookout for the kind of possibilities that things might be done that I didn't feel were in my son's best interest. (Parent)

\section{Severe: disintegration of working relationships}

By the time a conflict reached this level of escalation, interviewees reported that they no longer felt in control. Terms such as 'win' and 'lose' were used to describe the intended outcome.

Child is no longer the focus: At the most severe level, the focus often ceased to be on the best interests of the child. Clinicians cited examples of court action garnering publicity and empathy, or where a child's death resulted in significant financial loss for the family.

You just get a gut feeling that the arguments are moving away from the central core of the child. (Consultant paediatrician)

Clinicians identified that at times a specialist's desire to pursue a specific area of medical research became more prominent than the child's best interest:

Actually it can be difficult for us to disentangle what's in the child's best interests and what is us wanting to get our own way. Often there are many more than one way of managing a situation, and we have our preferred way, and some people are very dogmatic about that. (Consultant paediatrician)

Conflict takes on a life of its own: In a number of cases where conflict escalation was described, participants noted that the focus of both families and health professionals shifted from the child towards the conflict itself:

It was almost as if [the parents] were dancing to a different tune, because they weren't engaged with the child's day-to-day care; they were more preoccupied with winning their [court] case. (Paediatrician)

Physical and verbal threats: Threats were formulated as both personal (direct or threatened physical attack) and professional (threats to report clinicians to the press, or professional regulators).

I have a child on a ventilator here, and I think I am doing the wrong thing but the family is determined that I go ahead. If I stop treating that child and the child dies then, front page of The Daily Mail, and the GMC and a police investigation for murder or manslaughter. [...] It's not an experience that you want to even contemplate. (Consultant paediatrician, PICU)

In several instances, the press was involved in documenting the conflict, acting as advocates for the family's point of view.

Verbal abuse was apparent within this phase and physical attacks had also occurred.

I ended up shouting at an SHO, saying, what's this blood test for? (Parent)

[There] must have been about ten of them in there shouting, ranting, screaming at us and hitting, and just completely out of the blue, taken from behind...I'd been beaten black and blue. (Consultant paediatrician).

\section{Escalation}

A number of participants described how conflicts escalated. The following quotations illustrate escalation through the three phases. First, relationships begin to deteriorate. Then, the father begins to micromanage his child's care and finally, exhibits threatening behaviour.

There's a slight mistrust in the room already because 'well we've heard lots of different things'...It takes a number of weeks to get the diagnosis and you can see in their faces, they begin to think they lose their trust in you and you begin to think that you're incompetent 
[The father] would take the [electronic note system] and go through the screens to see what had happened, when and what reaction had been happening and at the nurse's comments and then write everything down in a book.

The father came with a camera and shoved it up everybody's nose and took photos of everybody. They were both screaming "murderers, murderers" at everybody, photographing the equipment, photographing the monitors, none of the nursing staff wanted to work there, the level of stress was enormous" [...] [The father] physically pushed the nurses. (Consultant, PICU).

While data collection focused on conflict escalation, some respondents spoke about their experiences of de-escalating conflict, including using communication skills and making time for difficult conversations:

Time, patience and respect. [...] You have to show that you understand and respect their position absolutely, and although you may not be able to agree with it, that you still got that real deep understanding of what they are doing, what are they trying to achieve, and why they are trying to achieve it. (Consultant, PICU)

\section{DISCUSSION}

This paper offers an empirically-derived framework for understanding conflict escalation in paediatric services and identifies three levels through which families and clinical teams progress on the way to a complete breakdown of trust.

The framework resonates with the literature on the content and outcome of conflict; for example, suboptimal communication has a recognised role in conflict. ${ }^{8}{ }^{24}$ Indeed, the origins of conflict in patients in long-term paediatric intensive care identifies poor communication, unavailability of parents and disagreements over the care plan as key causes. ${ }^{8}$ At the extreme end, physical violence has also been documented as a recognised outcome of healthcare conflict. ${ }^{25}$ The incidence of conflict may rise as a result of medical advances, whereby the number of children requiring ongoing palliative care services ${ }^{13}$ is likely to increase, with a corresponding increase in the impact on families.

The framework resonates with Glasl's ${ }^{26}$ nine-step model of conflict escalation, which was developed in the context of international relations. Glasl argues that researching conflict causality is less fruitful than verifying the dynamics of the conflict situation, in order to inform the appropriate choice of intervention. The evidence from this paper suggests that early recognition can equip healthcare teams to recognise mild or moderate conflict and choose appropriate interventions, to prevent further escalation. Further studies are warranted to test the model as a way of enabling healthcare teams to identify conflict at its earliest stages. However, if conflict cannot be resolved, then external interventions such as referral to a clinical ethics committee, ${ }^{27}$ mediation ${ }^{28}$ or court action may be necessary.

The study only involved a small number of parents, and no children or young people. The sample did not include families at the most extreme end of the conflict, reflecting the legal restrictions which precluded the researchers from contacting families (eg, following court action). A formal definition of conflict was not provided to interviewees.

\section{CONCLUSION}

There is an identifiable pattern of escalation to conflict in paediatrics. Insight into how conflicts escalate provides clinicians with a practical, evidence-based framework to identify the characteristics and phases of escalation. Further work is now required to pilot and evaluate the range of possible interventions which may be carried out within each phase in order to help health professionals recognise, manage and avoid future conflicts.

Twitter Follow Liz Forbat at @lizforbat / Sarah Barclay at @sarahbarclayldn

Contributors SB and BT designed the work and acquired the data; LF, BT and SB interpreted the data. LF, BT and SB drafted the work and revised it critically for intellectual content. LF, BT and SB approved the final version of the manuscript. $L F, B T$ and $S B$ agree to be accountable for all aspects of the work ensuring that questions related to the accuracy or integrity of any part of the work are appropriately investigated and resolved.

Funding The study was funded by the Department of Health. Grant: CPC30/94. The University of Stirling acted as sponsor for the research, providing insurance and indemnity.

Competing interests SB received a grant from the Department of Health during the conduct of the study and she is the director of the Medical Mediation Foundation-an organisation that provides mediation in situations where there is disagreement/conflict between patients and healthcare professionals. However, the manuscript focuses on how conflict escalates and only in the Discussion section refers to mediation as one potential solution.

Ethics approval Surrey REC (11/H1109/4).

Provenance and peer review Not commissioned; internally peer reviewed.

Data sharing statement Any requests for raw data should be directed to the corresponding author. At present, ethical approval is not in place for the sharing of data, therefore any such request would be subject to further NHS ethical approval processes.

Open Access This is an Open Access article distributed in accordance with the Creative Commons Attribution Non Commercial (CC BY-NC 4.0) license, which permits others to distribute, remix, adapt, build upon this work non-commercially, and license their derivative works on different terms, provided the original work is properly cited and the use is non-commercial. See: http://creativecommons.org/ licenses/by-nc/4.0/

\section{REFERENCES}

1 Brinkert R. A literature review of conflict communication causes, costs, benefits and interventions in nursing. J Nurs Manag 2010;18:145-56.

2 Almost J. Conflict within nursing work environments: concept analysis. J Adv Nurs 2006;53:444-53.

3 De Dreu C, Gelfand M. Conflicts in the workplace: sources, functions, and dynamics across multiple levels of analysis. In: De Dreu C, Gelfand M, eds. The psychology of conflict and conflict management in organizations. 1st edn. New York: CRC Press, 2007:3-54.

4 Farrell G. Aggression in clinical settings: nurses views. Jn Adv Nurs 1997:25:501-8.

5 Fassier T, Azoulay E. Conflicts and communication gaps in the intensive care unit. Curr Opin Crit Care 2010;16:654-65.

6 Azoulay E, Timsit JF, Sprung CL. Prevalence and factors of intensive care unit conflicts: the conflicus study. Am J Respir Crit Care Med 2009;180:853-60.

7 Breen C, Abernethy A, Abbott K, et al. Conflict associated with decisions to limit life-sustaining treatment in intensive care units. J Gen Intern Med 2001;16:283-9.

8 Studdert D, Burns J, Mello M, et al. Nature of conflict in the care of pediatric intensive care patients with prolonged stay. Pediatrics 2008;112:553-8.

9 Glaser A, Nicholson J, Taylor R, et al. Childhood cancer and proton beam therapy. BMJ 2014;349:5654.

10 O'Brien A. Lessons from the Ashya King case. BMJ 2014;349:5563.

11 Richards T. When doctors and patients disagree. BMJ 2014;349:5567.

12 Greene M, Adelman R. Beyond the Dyad: Communication in Triadic (and more) Medical Encounters. In: Martin L, DiMatteo M, eds. The Oxford handbook of health communication, behavior change, and treatment adherence. Oxford: Oxford Handbooks, 2013:136-54.

13 Fraser L, Miller M, Hain R, et al. Rising national prevalence of life-limiting conditions in children in England. Pediatrics 2012;129:923.

14 Costeloe K, Hennessy E, Gibson A, et al. The EPICure study: outcomes to discharge from hospital for infants born at the threshold of viability. Pediatrics 2000;104:659-71.

15 Choong K, Cupido C, Nelson E, et al. A framework for resolving disagreement during end of life care in the critical care unit. Clin Invest Med 2010;33:E240-53.

16 Meller S, Barclay S. Mediation: an approach to intractable disputes between parents and paediatricians. Arch Dis Child 2011;96:619-21.

17 Boyle $D$, Miller $P$, Forbes-Thompson SA. Communication and end-of-life care in the intensive care unit: patient, family, and clinician outcomes. Crit Care Nurs $Q$ 2005;28:302-16

18 Luce J, White D. The pressure to withhold or withdraw life-sustaining therapy from critically ill patients in the United States. Am I Respir Crit Care Med 2007;175:1104-8. 
19 Ward Platt M, Ward Platt A. Conflicts of care. Arch Dis Child 2005;90:331.

20 Brierley J, Linthicum J, Petros A. Should religious beliefs be allowed to stonewall a secular approach to withdrawing and withholding treatment in children? J Med Ethics 2013:39:573-7.

21 Birchley G. Deciding together? Best interests and shared decision-making in paediatric intensive care. Health Care Anal 2014:22:203-22.

22 Babbie E. The practice of social research. 9th edn. Belmont, CA: Wadsworth Thomson, 2001.

23 Braun V, Clarke V. Using thematic analysis in psychology. Qual Res Psyc 2006:3:77-101.
24 Wilmott W, Hocker J. Interpersonal conflict. 7th edn. Boston: McGraw Hill, 2007.

25 Hesketh K, Duncan S, Estabrooks C. Workplace violence in Alberta and British Columbia hospitals. Health Policy 2003;63:311-21.

26 Glasl F. The process of conflict escalation and roles of third parties. In: Bomers $G$, Peterson R, eds. Conflict management and industrial relations. 1st ed. The Hague: Kluwer Nijhoff Publishing, 1982:119-40.

27 Larcher V. Role of clinical ethics committees. Arch Dis Child 1999;81:104.

28 GMC. Treatment and care towards the end of life. Good practice in decision making. 2010. http://www.gmc-uk.org/Treatment_and_care_towards_the_ end_of_life_English_0914.pdf_48902105.pdf (accessed 10/4/2015). 